\title{
Chemoenzymatic Synthesis of Thiazolyl Peptide Natural Products Featuring an Enzyme-Catalyzed Formal [4 + 2] Cycloaddition
}

\author{
Walter J. Wever ${ }^{\dagger}$, Jonathan W. Bogart ${ }^{\dagger}$, Joshua A. Baccile ${ }^{\ddagger}$, Andrew N. Chan $§$, Frank C. \\ Schroeder ${ }^{\ddagger}$, and Albert A. Bowers ${ }^{*}, \dagger$ \\ tDivision of Chemical Biology and Medicinal Chemistry, Eshelman School of Pharmacy, \\ University of North Carolina at Chapel Hill, Chapel Hill, North Carolina 27599, United States \\ ‡Boyce Thompson Institute and Department of Chemistry and Chemical Biology, Cornell \\ University, Ithaca, New York 14853, United States \\ §Department of Chemistry, University of North Carolina at Chapel Hill, Chapel Hill, North Carolina \\ 27599, United States
}

\begin{abstract}
Thiocillins from Bacillus cereus ATCC 14579 are members of the well-known thiazolyl peptide class of natural product antibiotics, the biosynthesis of which has recently been shown to proceed via posttranslational modification of ribosomally encoded precursor peptides. It has long been hypothesized that the final step of thiazolyl peptide biosynthesis involves a formal [4 +2] cycloaddition between two dehydroalanines, a unique transformation that had eluded enzymatic characterization. Here we demonstrate that TclM, a single enzyme from the thiocillin biosynthetic pathway, catalyzes this transformation. To facilitate characterization of this new class of enzyme, we have developed a combined chemical and biological route to the complex peptide substrate, relying on chemical synthesis of a modified C-terminal fragment and coupling to a 38-residue leader peptide by means of native chemical ligation (NCL). This strategy, combined with active enzyme, provides a new chemoenzymatic route to this promising class of antibiotics.
\end{abstract}

Thiazolyl peptides are a growing class of highly modified, peptide-derived natural products with potent activity against antibiotic resistant bacteria, including methicillin-resistant Staphylococcus aureus and vancomycin-resistant Enterococci. ${ }^{1,2}$ Despite their potential therapeutic value, thiazolyl peptides have gone largely underdeveloped because of their generally poor solubility and bioavailability. Moreover, efforts to improve on these limiting properties by means of synthesis or chemical modification are hindered by the complex macrocyclic architecture of the compound class: thiazolyl peptides feature multiple azoline

(c) 2015 American Chemical Society

*Corresponding Author abower2@email.unc.edu.

The authors declare no competing financial interest.

Supporting Information

Experimental details, synthetic schemes, and figures. This material is available free of charge via the Internet at http://pubs.acs.org. 
heterocycles alternating with modified peptide side chains and cyclized on a trisubstituted pyridine (or piperidine) core (Figure 1).

Although a number of total syntheses have tackled the task of modified thiazolyl peptides, to date the most substantive improvements have come by means of semisynthetic strategies. ${ }^{3-7}$ Researchers at Novartis installed new solubilizing functionalities at the C-terminus of Streptomycete-derived GE2270A, yielding LFF571, a derivative currently in phase-II clinical trials for treatment of Clostridium difficile. ${ }^{8}$ Nevertheless, the key central macrocycle, constituting the majority of the drug pharmacophore, remains largely intractable to semisynthesis, limiting LFF571 solubility and efficacy to infections of the upper gastrointestinal tract.

Thiazolyl peptides are ribosomally synthesized and posttranslationally modified peptide natural products (RiPPs). ${ }^{9}$ They are biosynthesized from a precursor peptide containing an $\mathrm{N}$-terminal leader and a C-terminal core peptide motif. Knockout studies in Bacillus cereus ATCC 14579 have demonstrated the importance of the putative enzyme TclM in late-stage biosynthetic cyclization of this group of thiazolyl peptides. ${ }^{10-12} \mathrm{TclM}$ presents a potentially unique enzymatic activity: the long-hypothesized formal [4 + 2] cycloaddition between two dehydroalanines (Dhas) to generate the substituted pyridine core of the thiocillins. ${ }^{13-15}$ This putative "hetero-Diels-Alderase" activity is unique from both enzymatic and purely synthetic standpoints. In terms of enzymology, very few such "Diels-Alderases" are known, let alone members effecting a heteroannulative version of the chemistry. Enzymes that have been characterized as potential "Diels-Alderases" 16 often enhance spontaneous chemical cyclizations (e.g., $\mathrm{SpnF}^{17}$ and $\mathrm{VstJ}^{18}$ ), yet the proposed transformation of TclM is demonstrably nonspontaneous: Moody and co-workers have induced this chemistry on simple substrates by severe microwave irradiation. ${ }^{19}$ From a synthetic standpoint, TclM could provide a mild, late-stage route to the thiazolyl peptide core and allow access to new soluble derivatives. Herein we develop a combined chemical and biological strategy to access a leader-peptide-conjugated, doubly dehydrated substrate for TclM and demonstrate in vitro the ability of TclM to catalyze a formal [4 +2] cycloaddition to form the mature pyridine ring.

Previous experiments in our lab suggested that the leader peptide is necessary for TclM modification of the putative substrate, but solid-phase peptide synthesis (SPPS) of a full 52residue substrate with thiazolyl and dehydroamino acid residues seemed daunting, even with current SPPS technology. SPPS of the full substrate would also necessitate complete resynthesis of C-terminal variants for structure-activity probing of TclM. We therefore devised a strategy involving separate preparations of the C-terminal-modified component and the $\mathrm{N}$-terminal leader peptide (Figure 2a). The fully modified $\mathrm{C}$-terminal fragment could be prepared by total chemical synthesis, with cysteine side chains as surrogates for the required dehydroalanine residues. The use of cysteine at the $\mathrm{N}$-terminus of the modified fragment would allow coupling to an intein-derived thioester of the leader peptide via native chemical ligation (NCL). Upon coupling, cysteine side chains could be converted to Dhas by a bisalkylation/elimination protocol. ${ }^{20}$ 
We chose to prepare a simplified C-terminal fragment containing all six thiazoles of the natural thiocillin but with alanines used in place of threonines 4 and 6 and valine 8 and an ethyl ester in place of the two modified threonines at the C-terminus. Previous efforts had indicated that TclM would be permissive to alanine substitution at these sites, although these analogues would likely not be antibiotically active. ${ }^{12}$ This hexathiazole precursor could be built by adapted protocols from previous total syntheses by Bagley, Ciufolini, and Nicolaou (see the Supporting Information (SI)). ${ }^{3-5,7,21}$ Although we anticipate that this route will be readily amenable to the solid phase, we employed a block solution-phase synthesis. The desired product was obtained in good yield over seven steps (longest linear sequence from the building blocks; see the SI) and could then be deprotected to give compound $\mathbf{1 2}$.

The 38-residue leader peptide was cloned into vector pETXSH (P. Loll lab) containing a Cterminally His $_{6}$-tagged Mycobacterium xenopi intein. ${ }^{22}$ This could be expressed and purified by $\mathrm{Ni}$ affinity chromatography and cleaved to afford the 2-mercaptoethanesulfonate (Mesna) thioester. Subtractive purification gave the pure thioester, which was buffer-exchanged and coupled to an excess of hexathiazole 12. Elimination to give compound $\mathbf{1 6}$ could be carried out under conditions published by Davis and co-workers. ${ }^{20}$ The structure of the final precursor was confirmed by LC/MS (Figure 2c) and rigorously characterized by MS/MS fragmentation (see the SI).

To evaluate the ability of TclM to effect the formal [4 +2] cycloaddition of the two Dhas, the $t c l M$ gene was amplified from genomic DNA isolated from B. cereus ATCC 14579 and subcloned for translation as the $\mathrm{N}$-terminal $\mathrm{His}_{6} \mathrm{MBP}$-tagged fusion protein. Soluble protein was obtained in over $90 \%$ purity after Ni-NTA affinity and size-exclusion chromatography followed by tobacco etch virus (TEV) cleavage of the tag (Figure 3a and the SI). Although TclM does not have any obvious predicted cofactor binding pocket, we note that the purified protein did not appear to have any unusual absorbance in the visible-light range. Assays for the putative cycloaddition were conducted in a HEPES buffer at $\mathrm{pH} 7.2$ and room temperature. Time points were taken at $4 \mathrm{~h}$ intervals and analyzed by high-resolution QTOF LC/MS and UV-vis (Figure $3 \mathrm{~b}$ and the SI). Over course of the reaction, a new peak grew in at $350 \mathrm{~nm}$, consistent with the known, distinctive absorbance of the trisubstituted pyridine core in the thiazolyl peptides.

At $20 \mathrm{~h}$, all of the starting material $\mathbf{1 6}$ was consumed in the presence of TclM, and the new peak at $350 \mathrm{~nm}$ ceased to increase. The observed peak at $\mathrm{m} / \mathrm{z} 962.1171$ matches within instrumental error the value for $\left[\mathrm{M}+\mathrm{H}^{+}\right]$of expected product $17(\mathrm{~m} / \mathrm{z}$ 962.1118) and exhibits the distinctive MS/MS fragmentation pattern of thiazolyl peptides (see the SI). ${ }^{11}$ We further scaled up the enzymatic reaction and were able to isolate milligram quantities of product under unoptimized conditions to facilitate complete characterization via twodimensional NMR spectroscopy. For example, signals representing the newly formed pyridine protons can be clearly seen in the aromatic region, confirming the formation of the trithiazolylpyridine core (Figure $3 \mathrm{~d}$ and the SI). This compound was absent from all controls, including those with heat-denatured enzyme or prolonged (multiple days) solution without enzyme. 
A potential mechanism for the TclM reaction is illustrated in Figure 4. As drawn, the reaction involves concerted cyclization via a stabilized tautomer of the amide carbonyl (imidic acid tautomer). Alternatively, the mechanism could proceed in a stepwise manner, allowing nucleophilic attack from a stabilized $a$-carbanion of the formal $2 \pi$ component into an imidocarbonyl intermediate. Regardless of the mechanism, stepwise or concerted, to arrive at the final product, the putative cyclic intermediate would have to undergo aromatization by elimination of water and/or the leader peptide carboxamide; both steps may be spontaneous. We searched LC/MS traces for peaks that could represent any putative intermediates but found none of the anticipated masses, suggesting that either these intermediates are short-lived or else TclM itself catalyzes the aromatization.

This work provides direct evidence of the key role of TclM in the formal [4 + 2] cycloaddition to form the trithiazolylpyridine core of the thiocillins and most thiazolyl peptides. Our work further represents the first functional characterization of a member of this new class of enzymes. TclM and its homologues are remarkable in that they show little or no homology to members of other known enzyme classes. Even between members of the family, homology is low (14/31\% identity/similarity to the nearest homologue, TsrE). ${ }^{10}$ Remarkably, TclM is capable of carrying out the formal addition by itself, without accessory proteins or cofactors.

In conclusion, we have demonstrated that TclM catalyzes the formation of the trisubstituted pyridine core of an artificial thiazolyl peptide from a leader-peptide-bound substrate. Mechanistically, the reaction can be drawn as a formal [4 +2] cycloaddition between two Dhas with subsequent aromatization, but the exact mechanism, whether stepwise or concerted, is still undetermined. Substrate specificity and enzyme efficiency as well as a detailed mechanistic understanding of this new class of enzymes are subjects of ongoing efforts in our lab. We have also demonstrated a chemoenzymatic route to this attractive class of natural products; we anticipate that this route will allow the preparation of new and improved analogues that are not accessible by synthetic or semisynthetic methods.

\section{Supplementary Material}

Refer to Web version on PubMed Central for supplementary material.

\section{Acknowledgments}

The authors thank Scott Allen, Stephen Frye, Harold Kohn, Bo Li, Chris Neumann, and Chris Walsh for informative discussions and careful reading of the manuscript. A.A.B. is a Beckman Young Investigator and acknowledges support by the Arnold and Mabel Beckman Foundation. Additional support was provided by NIH Grants R01GM112739 (F.C.S.) and T32GM008500 (J.A.B.).

\section{References}

1. Walsh CT, Acker MG, Bowers AA. J Biol Chem. 2010; 285:27525. [PubMed: 20522549]

2. Just-Baringo X, Albericio F, Alvarez M. Angew Chem, Int Ed. 2014; 53:6602.

3. Nicolaou KC, Zou B, Dethe DH, Li DB, Chen DYK. Angew Chem, Int Ed. 2006; 45:7786.

4. Nicolaou KC, Zak M, Safina BS, Estrada AA, Lee SH, Nevalainen M. J Am Chem Soc. 2005; 127:11176. [PubMed: 16076225] 
5. Nicolaou KC, Safina BS, Zak M, Lee SH, Nevalainen M, Bella M, Estrada AA, Funke C, Zécri FJ, Bulat S. J Am Chem Soc. 2005; 127:11159. [PubMed: 16076224]

6. Gross S, Nguyen F, Bierschenk M, Sohmen D, Menzel T, Antes I, Wilson DN, Bach T. ChemMedChem. 2013; 8:1954. [PubMed: 24106106]

7. Ciufolini MA, Lefranc D. Nat Prod Rep. 2010; 27:330. [PubMed: 20179875]

8. LaMarche MJ, Leeds JA, Dzink-Fox J, Gangl E, Krastel P, Neckermann G, Palestrant D, Patane MA, Rann EM, Tiamfook S, Yu D. J Med Chem. 2012; 55:6934. [PubMed: 22812377]

9. Bindman, NA.; van der Donk, WA. Natural Products: Discourse, Diversity, and Design. Osbourn, A.; Goos, RJ.; Carter, GT., editors. Wiley-Blackwell; Oxford, U.K: 2014. p. 197-217.

10. Bowers AA, Walsh CT, Acker MG. J Am Chem Soc. 2010; 132:12182. [PubMed: 20707374]

11. Bowers AA, Acker MG, Young TS, Walsh CT. J Am Chem Soc. 2012; 134:10313. [PubMed: 22686940]

12. Bowers AA, Acker MG, Koglin A, Walsh CT. J Am Chem Soc. 2010; 132:7519. [PubMed: 20455532]

13. Mocek U, Zeng Z, O’Hagan D, Zhou P, Fan LDG, Beale JM, Floss HG. J Am Chem Soc. 1993; 115:7992.

14. Mocek U, Knaggs AR, Tsuchiya R, Nguyen T, Beale JM, Floss HG. J Am Chem Soc. 1993; 115:7557.

15. Bycroft BW, Gowland MS. J Chem Soc, Chem Commun. 1978:256.

16. Kelly WL. Org Biomol Chem. 2008; 6:4483. [PubMed: 19039353]

17. Kim HJ, Ruszczycky MW, Choi SH, Liu YN, Liu HW. Nature. 2011; 473:109. [PubMed: 21544146]

18. Hashimoto T, Hashimoto J, Teruya K, Hirano T, Shin-Ya K, Ikeda H, Liu HW, Nishiyama M, Kuzuyama T. J Am Chem Soc. 2015; 137:572. [PubMed: 25551461]

19. Moody CJ, Hughes RA, Thompson SP, Alcaraz L. Chem Commun. 2002:1760.

20. Chalker JM, Gunnoo SB, Boutureira O, Gerstberger SC, Fernández-González M, Bernardes GJL, Griffin L, Hailu H, Schofield CJ, Davis BG. Chem Sci. 2011; 2:1666.

21. Bagley MC, Bashford KE, Hesketh CL, Moody CJ. J Am Chem Soc. 2000; 122:3301.

22. Economou NJN, Nahoum VV, Weeks SDS, Grasty KCK, Zentner IJI, Townsend TMT, Bhuiya MWM, Cocklin SS, Loll PJP. J Am Chem Soc. 2012; 134:4637. [PubMed: 22352468] 
a



Thiocillins $\quad \mathrm{R}_{1}=\mathrm{H}$ or $\mathrm{CH}_{3} \quad \mathrm{R}_{2}=\mathrm{H}$ or OH $\quad \mathrm{R}_{3}=\sum^{25}$ or $>+\cdots \mathrm{OH}$

b Thiocillin Gene Cluster from B. cereus ATCC 14579:

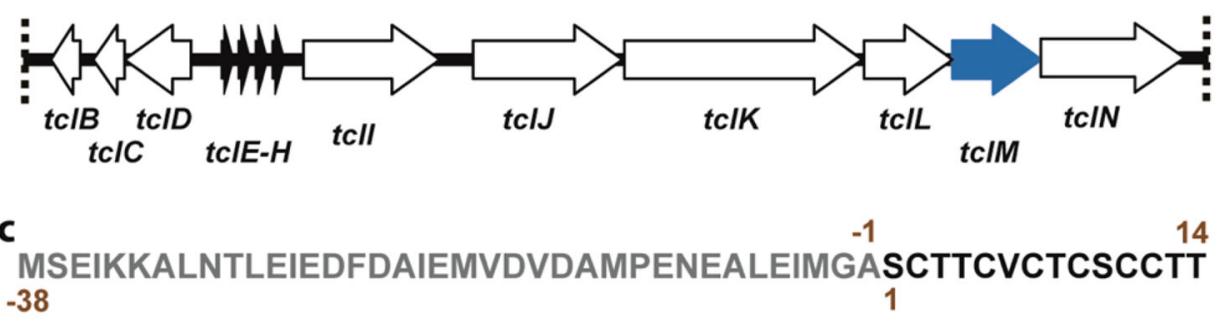

Figure 1.

(a) Biosynthesis of thiocillins from a modified peptide. LP = leader peptide. (b) Thiocillin gene cluster from Bacillus cereus ATCC 14579. Open reading frames encoding key posttranslational enzymes are shown. (c) Sequence of the 52-residue precursor featuring a 38residue leader sequence (gray) and a 14-residue core peptide (black). 

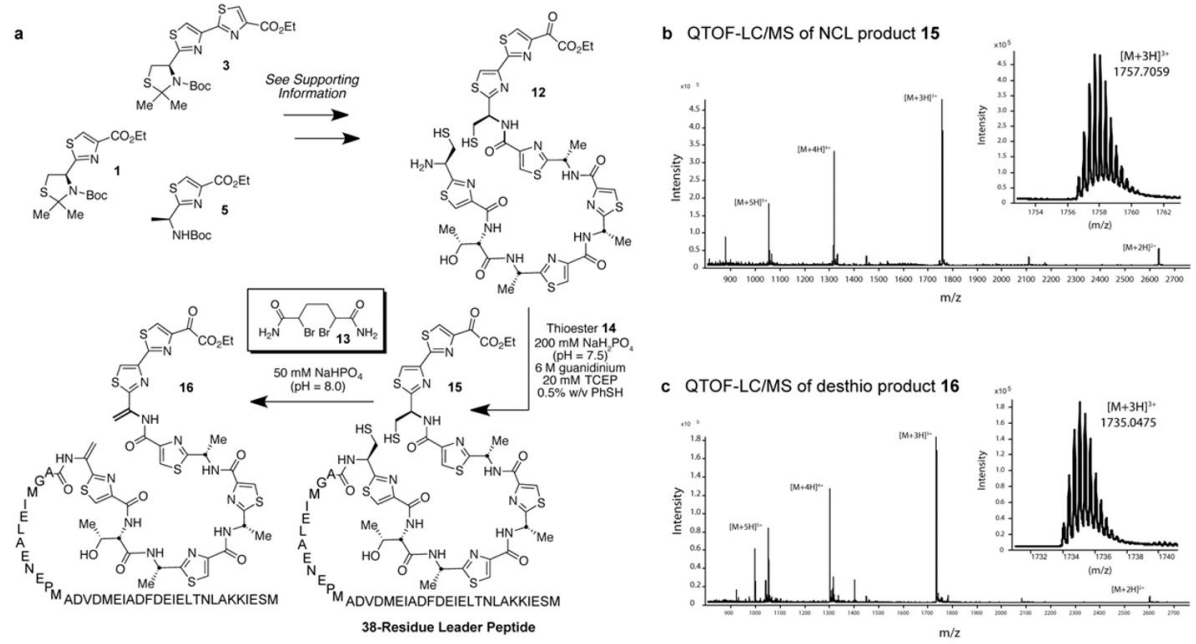

Figure 2.

(a) Synthesis of the TclM substrate by thiophenol-catalyzed native chemical ligation and sulfhydryl elimination with dibromoadipamide. (b, c) QTOF-MS data of (b) NCL product 15 and (c) elimination product 16. 

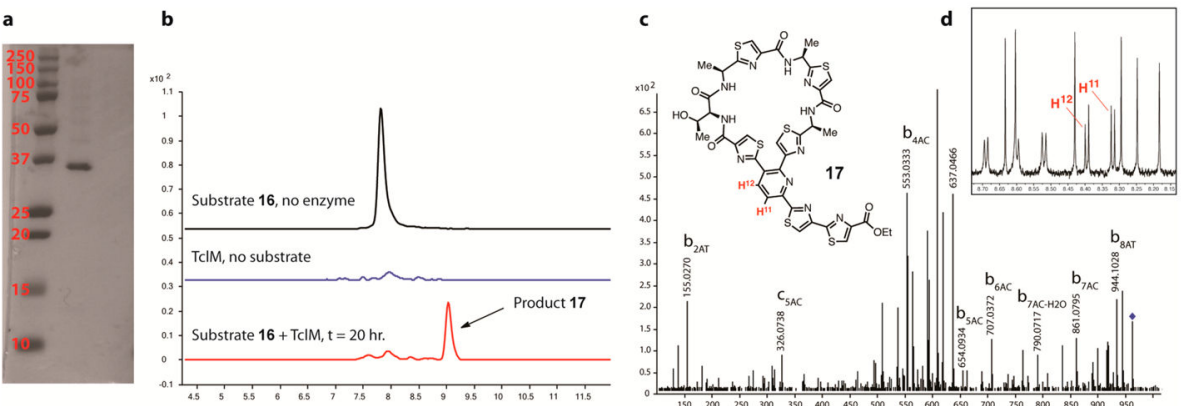

Figure 3.

(a) SDS-PAGE of purified recombinant TclM. (b) Overlaid extracted ion chromatograms of TclM substrate and TclM assay after $20 \mathrm{~h}$ of incubation. The labeled peak indicates the newly formed thiazolyl peptide. (c) MS/MS spectrum of the isolated artificial thiazolyl peptide prepared by the chemoenzymatic method. Ions are labeled according to convention for the cyclic peptide. (d) Aromatic region of the ${ }^{1} \mathrm{H}$ NMR spectrum showing new pyridine protons. 

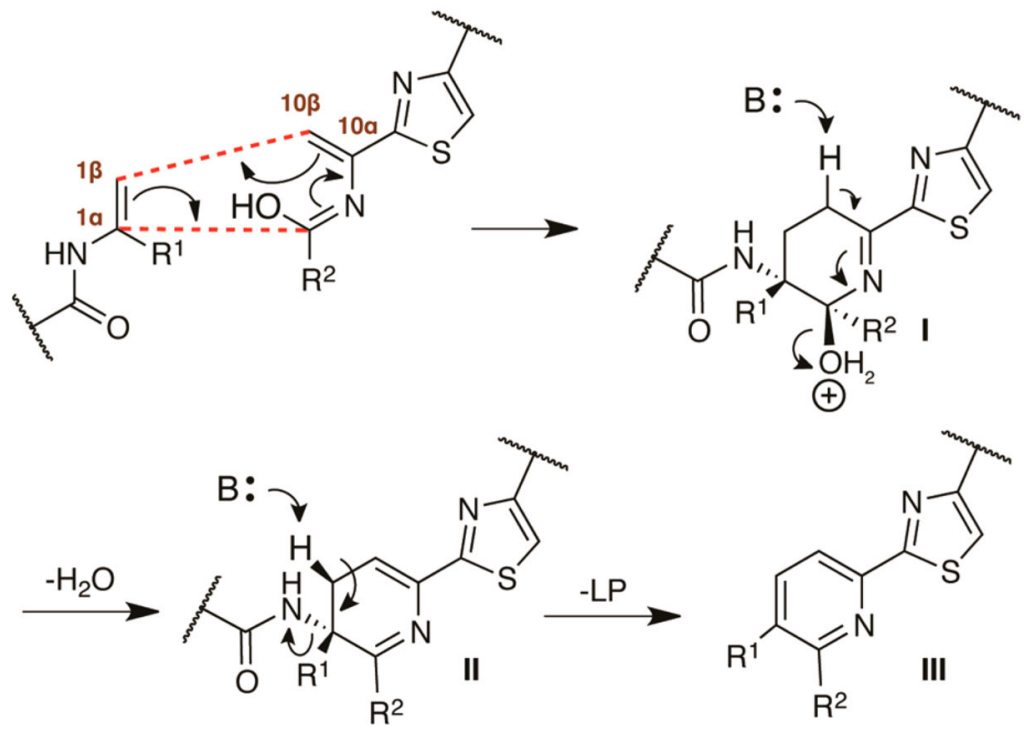

Figure 4.

Proposed mechanism of formal [4 +2] cycloaddition catalyzed by TclM. The reaction may proceed in concerted fashion from the imidic acid, as illustrated, or else stepwise (not shown) to yield putative intermediate $\mathbf{I}$. This undergoes further elimination/aromatization to the trithiazolylpyridine core of the thiocillins (structure III, R1, R2 = thiazole). 